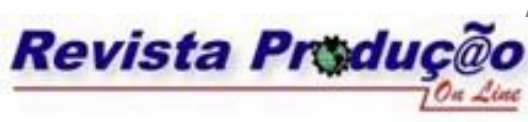

\title{
UMA ABORDAGEM PARA IMPLEMENTAÇÃ O DE QUALIDADE ASSEGURADA NO FORNECIMENTO, BASEADA EM ANÁLISE DE CAPACIDADE: UM ESTUDO DE CASO EM UMA EMPRESA DO SETOR AUTOMOTIVO
}

\author{
AN APPROACH FOR IMPLEMENTATION OF QUALITY \\ ASSURANCE ON SUPPLYING, BASED ON CAPACITY ANALYSIS: A \\ CASE STUDY ON AN ENTERPRISE OF THE AUTOMOTIVE BRANCH
}

\author{
André Diehl de Deus \\ Universidade do Vale do Rio dos Sinos - UNISINOS \\ Engenheiro de Produção-Mecânica (UNISINOS) \\ Unidade Acadêmica de Pesquisa e Pós-Graduação \\ diehld@unisinos.br \\ Guilherme Luís Roehe Vaccaro \\ Universidade do Vale do Rio dos Sinos - UNISINOS \\ Doutor em Ciência da Computação (PCC/UFRGS) \\ guilhermev@unisinos.br
}

\begin{abstract}
RESUMO
Este trabalho relata um estudo de caso no qual é investigada a aplicação de uma abordagem estatística para implementação da estratégia de Qualidade Assegurada no processo de inspeção de produtos e componentes produtivos, recebidos por uma empresa do ramo automotivo. A abordagem é apresentada sob a ótica da redução de desperdícios e do controle estatístico de processo, mais especificamente na análise de capacidade. A pesquisa foi desenvolvida com base descritiva, fundamentada em referenciais técnicos da indústria automotiva. A aplicação foi realizada na forma de um estudo de caso em uma empresa sistemista de um complexo automotivo nacional. Os resultados obtidos permitiram a identificação de classes de fornecedores e o aumento do foco nos esforços de melhorias de fornecedores. O artigo apresenta ainda uma análise a posteriori, decorrido um ano da implementação da abordagem, procurando discutir a sustentação dos resultados obtidos pela empresa. Finalmente apresenta considerações sobre sua aplicabilidade nesse ambiente e em outros ambientes produtivos.
\end{abstract}


Palavras chave: Qualidade Assegurada, Certificação de Fornecedores, Capacidade de Processo, Inspeção, Perdas, Estudo de Caso.

\begin{abstract}
This paper presents a case study in which a statistical approach is investigated for Quality Assurance implementation, on inspection of products and productive parts process, on an automotive company. The approach is presented under the waste reduction optics and the statistical process control, more specifically in the capability analysis. The research was developed with descriptive base, based on technician reference of the automotive industry. The application was a case study in an automotive complex's company of a national automotive complex. The obtained results allowed identifying classes of suppliers and provide focus in the efforts of quality improvements of suppliers. The paper also presents an analysis after one year of implementation of the approach, in order to discuss the sustainability of the results on the context of the company. Finally it presents considerations on its applicability in this environment and other productive environments.
\end{abstract}

Keywords: Quality Assurance, Supplier Certification, Process Capability, Inspection, Wastes, Case Study.

\title{
1. Introdução
}

A indústria automotiva brasileira apresenta uma cadeia estruturada de fornecimento e produção estabelecida desde os anos 1940 e revigorada desde a década de 1990. Segundo dados da Associação Nacional dos Fabricantes de Veículos Automotores (ANFAVEA, 2008), a produção de autoveículos no Brasil cresceu $45 \%$ nos últimos cinco anos, sendo que no ano de 2007, o recorde mensal de produção foi de quase 300.000 veículos. Os dados mostram que o segmento encontrava-se aquecido e promissor, apresentando um perfil de crescimento até meados do ano de 2008. No primeiro bimestre de 2008, o volume de unidades produzidas foi de 502.368 (ANFAVEA, 2008). A crise econômica estabelecida no setor automotivo a partir de outubro do ano passado, fez com que as demandas do mercado, e consequentemente os volumes de produção, da cadeia automotiva fossem reduzidos drasticamente. A prática de férias coletivas e days off tornou-se constante e a necessidade de aprimorar os processos, tornando-os cada vez mais enxutos, tornou-se ainda mais visível no momento de crise. Ao visar a garantia da sustentabilidade nas vendas e empregos do setor, o governo nacional 


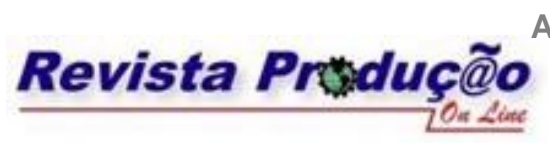

Associação Brasileira de Engenharía de Produção - ABEPRO

Universidade Federal de Santa Catarina - UFSC

www.producaoonline.org.br

ISSN 1676 - 1901 / Vol. IX/ Num.IV/ 2009

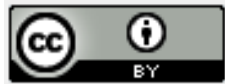

aprovou a redução na taxa de IPI aplicada a essa categoria de produtos. Porém, como a manutenção desta redução tem um prazo limitado, faz-se necessário atuar nos processos internos como forma de reduzir desperdícios e garantir a sobrevivência das organizações.

Considerada a estrutura da cadeia e as características de globalização desse mercado, cada vez mais a relação custo-benefício é exposta. Por conseqüência, a pressão por manutenção ou elevação dos padrões de qualidade e por redução de custos torna-se maior, impingindo às empresas denominadas sistemistas pouca margem para erros de produção ou de recebimento de matérias-primas.

O fornecimento de componentes representa parte significante do processo produtivo, principalmente no caso da indústria automotiva. Dadas as características dessa indústria em particular, freqüentemente cada componente somente é fornecido por uma empresa, havendo necessidade de constante monitoramento e qualificação dos fornecedores. Ocorre que as práticas de gestão de fornecedores utilizadas podem ser diversas, sendo adequadas, em maior ou menor grau, a certos tipos de contextos organizacionais. No caso da indústria automotiva, o uso de referenciais baseados em manuais e técnicas dos sistemas da qualidade (tipicamente Planejamento Avançado da Qualidade do Produto, APQP; Análise do Sistema de Medição, MSA; Controle Estatístico do Processo, CEP; Análise de Modo e Feito de Falha Potencial, FMEA) é corrente e plenamente incorporado ao contexto cultural desse tipo de organização. Assim, é razoável justificar a busca de uma abordagem para a gestão de fornecedores fundamentada nos mesmos conceitos e práticas utilizados para a gestão de processos industriais, neste contexto.

A empresa objeto deste estudo é líder mundial no fornecimento de interiores automotivos para montadoras de veículos, e fornece seus produtos no sistema de produção just in sequence. A unidade estudada localiza-se em Gravataí, Rio Grande do Sul. Suas operações iniciaram no ano de 2000. No país, a empresa também possui plantas em São Paulo, Minas Gerais e Bahia. Com um sistema de qualidade implementado, é certificada nas normas ISO 9001:2000, ISO TS 16949:2002 e ISO 14001:2004.

O estudo realizado buscou identificar características relevantes do processo de certificação de fornecedores da empresa, visto que estes possuem impacto significante na qualidade dos produtos gerados e sua melhoria contribui para a redução de custos operacionais e logísticos. Durante o desenvolvimento do trabalho buscou-se avaliar e 


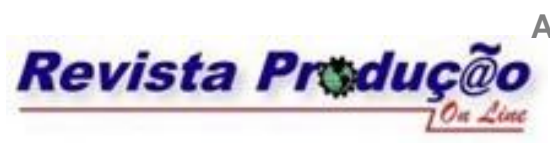

Associação Brasileira de Engenharía de Produção - ABEPRO

Universidade Federal de Santa Catarina - UFSC

www.producaoonline.org.br

ISSN 1676 - 1901 / Vol. IX/ Num.IV/ 2009

(i)

desenvolver o senso crítico do ambiente estudado em torno de conceitos teóricos e práticas das organizações, de modo a proporcionar para a empresa objeto do estudo uma análise crítica acerca do seu sistema de inspeção de recebimento no que diz respeito à qualidade assegurada.

O restante do artigo é estruturado da seguinte forma: revisão do estado da arte sobre qualidade assegurada e estratégias operacionais relacionadas ao processo de inspeção de recebimento no segmento de estudo; detalhamento do ambiente de inspeção e certificação da qualidade da empresa, descrição das modificações propostas e resultados do estudo. $\mathrm{O}$ artigo finaliza com a análise crítica dos resultados obtidos e tece conclusões com o sentido de colaborar com a pesquisa acadêmica na área.

\section{Referencial Teórico}

O estudo realizado fundamenta-se em princípios de eliminação de perdas do Sistema Toyota de Produção (STP), de certificação de fornecedores quanto ao Sistema da Qualidade e com relação à qualidade assegurada. Estes conceitos serão brevemente discutidos a seguir.

\subsection{Perdas e o Sistema Toyota de Produção}

Shingo (1996) apresenta o estudo das perdas (ou desperdícios) no sistema de produção e classifica os desperdícios em sete tipos:

- por Superprodução, referentes à produção de itens acima do necessário ou antecipadamente;

- por Transporte, referentes às atividades de movimentação de materiais ou informações, as quais usualmente não adicionam valor ao produto;

- por Processamento, correspondendo às atividades de transformação desnecessárias para que o produto adquira suas características básicas de qualidade, ou seja, no trabalho que gera partes, detalhes ou transformações desnecessárias ao produto. Evidentemente, uma transformação desnecessária no produto/processo ou a confecção de partes dispensáveis para se conseguir as funções básicas constituem desperdício, por mais eficiente que seja o processo. A eliminação destas deficiências de processo deve ser completa e pode ser 
atingida por meio de técnicas de análise do valor de produto e de processo;

- por Fabricação de Produtos Defeituosos, correspondendo à confecção de itens fora das especificações. Este tipo de desperdício talvez seja o mais facilmente identificável e mensurável, mas não o menos importante. Uma das maiores necessidades da empresa moderna é a busca incessante pela excelência na eficiência produtiva. Sem isto, ela não se torna competitiva. O trabalho realizado deve ser único e somente quando necessário, evitando qualquer tipo de contato posterior para a execução de revisões ou retrabalhos;

- por Movimentação, relacionados à movimentação inútil na execução das atividades, ou seja, á ineficiência da operação propriamente dita. O nome deriva dos estudos do movimento, de Gilbreth (GILBRETH e KENT, 1911), para quem a ineficiência resulta de movimentações desnecessárias no trabalho de transformação. A mensuração deste desperdício está ligada à obtenção de padrões de desempenho para as operações, e sua eliminação é conseguida alcançando-se os padrões necessários e possíveis de executar, analisando conjuntamente a ergonomia dos movimentos;

- por Espera, relacionados a questões de sincronização da produção ou constituição de lotes elevados de processamento graças ao elevado tempo de preparação das tarefas, ou falhas no sistema de informações da organização. Para se evitar este desperdício deve-se ter acesso às informações necessárias com precisão e facilidade, além de investir em um processo confiável e sincronizado de produção;

- por Estoque, relacionados à existência de estoques, gerando custos financeiros para sua manutenção, custos devido à obsolescência dos itens estocados e, principalmente, custos de oportunidade pela perda de mercado futuro para a concorrência com menor lead time. A máxima redução possível de estoques é uma meta que possui impacto no desempenho da organização (SHINGO, 1996).

O conceito de perda produtiva permeia diversas discussões e com diferentes enfoques na cadeia automotiva. Wu (2003) apresenta um estudo exploratório na indústria automotiva americana e em empresas japonesas da mesma cadeia, comparando fornecedores que adotaram princípios de produção enxuta e outros que não adotaram esses princípios. $\mathrm{O}$ autor caracteriza elementos do sistema de produção, do sistema de distribuição, do sistema de transporte e da relação entre fornecedor e cliente. $O$ estudo indica que a classe de fornecedores que adota princípios de produção enxuta é diferenciada em todos os quesitos 


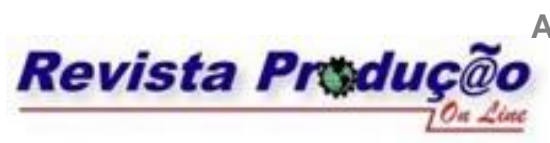

analisados e mais capaz de gerar reduções de custos logísticos a médio e longo prazo. Além disso, a prática de inclusão de cláusulas de penalidade por problemas de entrega e qualidade reforça a necessidade de compromisso com a redução de perdas, indicando benefícios para os relacionamentos de longo prazo que excedem a questão da eficiência produtiva.

Matson e Matson (2007) realizaram uma pesquisa com 100 empresas automotivas dos estados americanos do Tenessee e do Alabama, buscando identificar os principais problemas na adoção dos princípios de just-in-time (JIT) nessa cadeia. Os resultados indicaram, no que tange aos fornecedores de montadoras, que os principais problemas são: entregas no prazo, tempo de reação, qualidade dos itens fornecidos, lead time, falta de comunicação e atrasos relacionados a condições climáticas. Os autores concluem que os fornecedores desempenham um papel fundamental para o resultado de um sistema JIT e ponderam que a manutenção de contratos de longo prazo com poucos fornecedores pode resultar em melhores canais de comunicação, requerer menos acompanhamento e menos burocracia, podendo resultar em elevação da qualidade dos itens recebidos e redução de custos.

\subsection{Capitalismo Natural}

À abordagem proposta no STP soma-se a do capitalismo natural (HAWKEN, LOVINS e LOVINS, 2000), cujos conceitos básicos são apresentados a seguir. Esses autores têm um enfoque diferente sobre crescimento e desenvolvimento natural. Segundo eles, crescimento e desenvolvimento são tratados de tal maneira que a elevação do consumo é o fator de produção, crescimento e desenvolvimento. Ou seja, o capitalismo atual incentiva o consumo e, de certa forma, o desperdício para que a indústria possa produzir. Essa, por sua vez, é direcionada a lançar produtos novos, para incentivar os consumidores a se desfazerem dos "antigos" e adquirirem os mais modernos.

O desperdício, para Hawken, Lovins e Lovins (2000), tem um significado bem mais amplo que o pensamento tradicional de processos de produção, administração de custos ou projetos. Desperdício vai além da percepção de "o que é gasto e sem agregar valor ao produto ou serviço", ou seja, o que o cliente paga e não recebe. A palavra desperdício tem o significado ampliado para todo recurso que é mal usado ou é usado sem necessidade. A diferença reside em condenar o uso abusivo e descontrolado dos recursos naturais, que são base de sustentação de vida na Terra. Seguindo esse raciocínio, o autor orienta a seguir exemplos dados pela natureza para construir projetos e proceder a uma real eliminação dos 


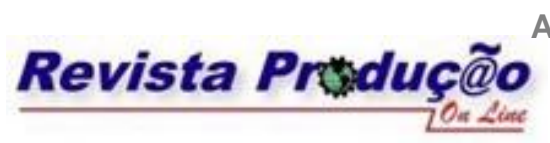

desperdícios. Sugere que se deveria abandonar a atual maneira de pensar e começar a pensar em maneiras de conviver em harmonia com o meio ambiente.

Recentemente Dahlmann, Brammer e Millington (2008) realizaram uma pesquisa com 167 empresas no Reino Unido, visando identificar a relação entre perdas ambientais e práticas de produção. Os autores identificaram uma tendência de busca por ações de redução dos impactos ambientais, mesmo em pequenas e médias empresas, ainda que muitas iniciativas não tenham sucesso imediato. Em particular, os autores citam que em certos casos tal busca ocorre por pressão dos elos finais da cadeia produtiva, como no caso da indústria automotiva.

Simpson, Power e Samson (2007) realizaram um estudo com empresas da cadeia automotiva australiana, identificando a efetividade da relação entre empresas fornecedoras e empresas clientes quanto às necessidades declaradas dos consumidores de desempenho ambiental ("green-supply"). Os autores identificaram que a pressão dos consumidores pode levar a investimentos de propósito específico, destinados a fomentar o comprometimento entre os elos da cadeia, no sentido da promoção de ambientes produtivos com maior desempenho ambiental, os quais poderiam, também, ser efetivados por meio da implementação da Qualidade Assegurada.

\subsection{Aspectos Normativos e Características da Cadeia Automotiva}

A adoção de sistemas e normas da qualidade é uma prática comum na indústria automotiva. Tal prática implica diferentes ações e abordagens no que tange a seleção e avaliação de fornecedores, conforme o segmento observado. Por exemplo, segundo Johnson (2002), aos fornecedores de primeiro nível das montadoras é requerida a adoção da ISO/TS 16949. Essa norma, por sua vez, requer a existência de um processo de avaliação de todos os fornecedores ou subcontratados. Com base em um survey realizado com 110 fornecedores de um sistemista da indústria automotiva americana esse autor pondera que a simples adoção dos elementos da norma não constitui uma abordagem abrangente, ou mesmo sustentável, em termos de qualidade assegurada. Segundo ele, a abordagem é demasiadamente focada no sistema e não nos resultados do sistema.

Os fatores que interferem no desenvolvimento de fornecedores excedem as questões normativas, passando pela necessidade de amadurecimento dos próprios fornecedores. Furlan, Grandinetti e Camuffo (2007) apresentam uma discussão baseada em um survey com 472 


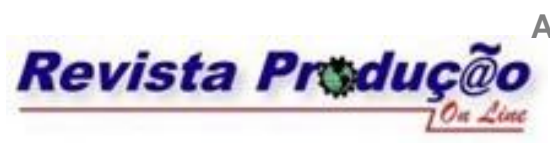

Associação Brasileira de Engenharia de Produção - ABEPRO

Universidade Federal de Santa Catarina - UFSC

www.producaoonline.org.br

ISSN 1676 - 1901 / Vol. IX/ Num.IV/ 2009

(i)

empresas e um estudo de caso múltiplo realizado com base em 10 empresas do nordeste da Itália, visando identificar perfis de evolução de empresas subcontratadas em cadeias produtivas. Os autores identificam, entre diferentes elementos, a presença de gestão dos suprimentos e de codificação do conhecimento como pré-requisitos para o desenvolvimento de um fornecedor subcontratado.

No país, a relação entre fornecedores e sistemistas apresenta-se entremeada com a relação interinstitucional promovida pelas associações de classe da indústria de autopeças. Mesquita, Lazzarini e Cronin (2008) realizaram um estudo quantitativo com 182 empresas da indústria de autopeças brasileira, objetivando identificar fatores de competitividade nesse ambiente. Os autores identificaram que a combinação de esforços de relacionamento entre elos da cadeia e o suporte de instituições de classe e governamentais são fundamentais para o desempenho da cadeia. Em particular, no país o suporte institucional dá condições para o desenvolvimento de relações de benefício mútuo entre empresas fornecedoras e clientes.

\subsection{Qualidade e Qualidade Assegurada}

O termo Qualidade vem do latim Qualitate, e é utilizado genericamente para referir a capacidade de um produto ou serviço em atender as expectativas de um indivíduo ou organização com relação a um padrão (tangível ou intangível) de satisfação. Objetivamente, qualidade pode ser referido como a adequação ao uso (JURAN, 1992; AKAO e MIZUNO, 1994) ou o inverso da variabilidade (MONTGOMERY, 2004). A qualidade de um produto ou serviço pode ser olhada de duas óticas: a do produtor e a do cliente. Do ponto de vista do produtor, a qualidade se associa à concepção e produção de um produto que vá ao encontro das necessidades do cliente. Do ponto de vista do cliente, a qualidade está associada ao valor e à utilidade reconhecidos ao produto, estando em alguns casos ligada ao preço. Sob este aspecto, a qualidade não é unidimensional: o cliente, em geral, avalia um produto tendo em conta várias das suas características simultaneamente.

Do ponto de vista das organizações, contudo, o conceito acordado de qualidade deve ser claro e objetivo. Isso significa que a empresa fornecedora deve estar ciente das necessidades de seus clientes e, em função dessas, definir os requisitos de qualidade do produto. O processo deve ser acompanhado e seu desempenho deve ser avaliado por procedimentos focados nessas características de qualidade percebida. 


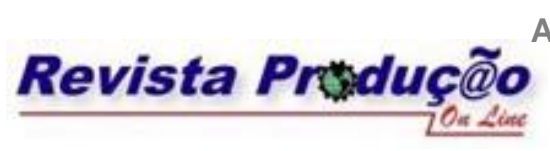

Associação Brasileira de Engenharia de Produção - ABEPRO

Universidade Federal de Santa Catarina - UFSC

www.producaoonline.org.br

ISSN 1676 - 1901 / Vol. IX/ Num.IV/ 2009

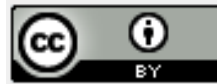

No relacionamento empresa-fornecedores, o acompanhamento pode se inverter. Nesses casos, a equipe de gestão dos fornecedores deve zelar pelas informações de qualidade de cada empresa fornecedora, praticando um método único de avaliação. Com isso, a empresa cliente terá parâmetros comparativos de desempenho nas diversas empresas e poderá atribuir graus diferenciados de esforço sobre a melhoria sobre seus fornecedores, gerindo melhor sua capacidade.

Na década de 60, nos EUA, foi estabelecido o conceito de Qualidade Assegurada ou garantia da qualidade, por fruto de força da lei, principalmente pela segurança operacional das instalações nucleares e equipamentos militares (CAMPOS, 1990). Sua ênfase está nos processos e ferramentas que detectam e previnem ocorrências de falhas. A existência de controle gera a necessidade de implantar padrões metodológicos para detectar, avaliar e continuamente observar a divergência em relação a metas estabelecidas.

No contexto da Qualidade Total, sistema o gerenciamento dos sistemas constitui um processo livre de problemas, fundamentado na atuação metódica sobre as causas fundamentais dos mesmos, de tal maneira a aperfeiçoar constantemente os sistemas. A padronização é a base do gerenciamento por sistemas (CAMPOS,1990). O gerenciamento por sistemas é a própria prática do controle da qualidade e a padronização tem uma importância fundamental no controle. Como as melhorias dependem de se ter uma rotina (controle de qualidade) implantada, decorre que a padronização é fundamental para todo o gerenciamento empresarial, tanto nas ações de rotina quanto nas melhorias.

De uma forma geral, primeiro deve-se controlar para, em seguida, assegurar. Conforme Silva (2003) a garantia da qualidade, ou Qualidade Assegurada, é o conjunto de ações sistemáticas ou planejadas que visam conferir um nível de confiança adequado aos serviços e produtos para que os mesmos venham a atender as necessidades relativas à qualidade. Na verdade a garantia da qualidade é uma filosofia de ação aliada a uma boa prática gerencial. É uma maneira de gerenciar pessoas que obriga a cada um ter, para com a empresa a que pertence, a postura que conduza fundamentalmente à compreensão de que adequar produtos e serviços a mercados, com qualidade assegurada, ocorre em um espaço técnico, político e cultural a ser definido. 


\subsection{A Adoção de Ferramentas Estatísticas}

Uma das formas de medir a estabilidade do processo de um fornecedor, durante o desenvolvimento e aprovação de novos produtos e/ou processos, é a adoção dos princípios e métodos do Controle Estatístico do Processo.

O resultado de um processo estável pode ser descrito pela manutenção, ao longo do tempo, de um padrão de comportamento, representado por um modelo probabilístico. O processo deve ser estável (sob controle estatístico) para que a distribuição seja útil na previsão dos resultados futuros. A distribuição será descrita em termos das características (estatísticas) calculadas a partir das medições das amostras tiradas do processo (MONTGOMERY, 2004).

Sob o ponto de vista da especificação técnica, as estatísticas de maior interesse estimam a localização da distribuição (ou centralização em relação à meta de especificação) e a dispersão com relação às necessidades e tolerâncias aceitas pelos clientes (limites de especificação). Em geral, a centralização é estimada pela média ou pela mediana da amostra. A dispersão em geral é estimada usando a amplitude ou o desvio padrão da amostra (MONTGOMERY e RUNGER, 2003).

A centralização e a dispersão do processo interagem com relação à produção de um produto aceitável. À medida que a posição do processo se desloca da meta de centralidade estabelecida, o espaço disponível para acomodar suas variações diminui, considerada a manutenção da mesma capacidade de produção de peças conformes. Uma mudança na posição, um aumento na dispersão ou uma combinação desses fatores pode levar o processo a produzir peças fora dos limites de especificação. Dependendo dos níveis de tolerância aceitáveis, um processo com tal configuração poderia não se qualificar para atender às necessidades do cliente (MONTGOMERY, 2004).

Para Montgomery (2004), um processo estável permite a avaliação de seu potencial de produção de unidades conformes por meio de indicadores de capacidade. Para esses indicadores serem efetivamente utilizados, as condições que os cercam devem ser entendidas. Se estas condições não são atendidas, as medidas terão pouco ou nenhum significado e podem induzir a erros na compreensão dos processos dos quais eles foram gerados. Os requisitos mínimos que as medidas de capacidade devem atender são: o processo do qual os dados foram obtidos deve ser estatisticamente estável, ou seja, as regras de controle estatístico de processo 


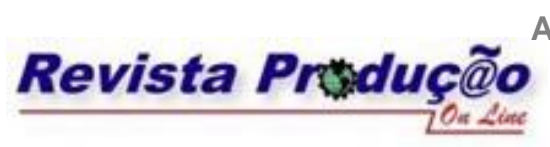

Associação Brasileira de Engenharía de Produção - ABEPRO

Universidade Federal de Santa Catarina - UFSC

www.producaoonline.org.br

ISSN 1676 - 1901 / Vol. IX/ Num.IV/ 2009

(i)

normalmente aceitas não devem ser violadas; as medições individuais dos dados obtidos do processo formam aproximadamente uma distribuição normal e as especificações se baseiam nos requisitos do cliente (MONTGOMERY, 2004).

Essencialmente, há dois tipos de indicadores para a estimação da capacidade projetada para o processo: Cp (capacidade nominal do processo) e Cpk (capacidade efetiva do processo). Há outros dois indicadores associados ao desempenho do processo: Pp (desempenho nominal do processo) e Ppk (desempenho efetivo do processo). Os índices de capacidade e desempenho têm interpretações semelhantes, sendo diferentes na forma de cálculo e nos pressupostos assumidos. Em geral, para a estimação da capacidade é assumido que o processo esteja estável e siga um padrão aproximadamente normal. Uma discussão sobre variação do processo usando índices de capacidade tem pouco valor para os processos instáveis. Para processos em que as premissas de normalidade não podem ser confirmadas, sugere-se (ASQC, 1991; MONTGOMERY e RUNGER, 2003) o uso dos índices de desempenho. Para fins deste trabalho, será usado o Ppk, calculado pela expressão (1)

$$
P p k=\min \left(\frac{L S E-\bar{X}}{3 S}, \frac{\bar{X}-L I E}{3 S}\right)
$$

onde $\bar{X}$ é a média do processo, LSE é o limite superior de especificação, LIE é o limite inferior de especificação e $S$ é o desvio padrão amostral. Este foi o indicador utilizado neste trabalho.

\section{Materiais e Métodos}

Conforme Vergara (2000), para classificação da pesquisa toma-se como base dois aspectos: os fins, ou objetivos, e os meios, ou procedimentos. Quanto aos fins, a pesquisa é descritiva. Apresenta de que forma uma empresa do ramo automotivo utiliza para qualificar a inspeção de produtos e componentes produtivos, em um sistema de recebimento. Quanto aos meios, a pesquisa é bibliográfica e um estudo de caso. Bibliográfica, porque para a fundamentação teórica foi feita uma pesquisa bibliográfica buscando-se base para melhor compreensão dos conceitos e abordagens disponíveis na literatura, no contexto estudado. E 


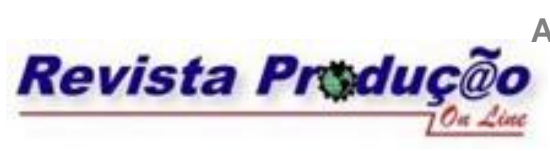

Associação Brasileira de Engenharía de Produção - ABEPRO

Universidade Federal de Santa Catarina - UFSC

www.producaoonline.org.br

ISSN 1676 - 1901 / Vol. IX/ Num.IV/ 2009

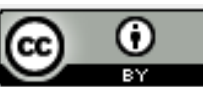

por fim, após a fundamentação teórica, a pesquisa foi estruturada através de um estudo de caso, que apresenta as estratégias de qualidade assegurada utilizadas pela empresa, relacionando-as às definições dos diversos autores citados.

O Estudo de Caso é um método de investigação que se caracteriza pela análise aprofundada de uma determinada realidade. Em relação aos estudos de caso, "representam a estratégia preferida quando se colocam questões do tipo "como" e "por que", quando o pesquisador tem pouco controle sobre os eventos e quando o foco se encontra em fenômenos contemporâneos inseridos em algum contexto da vida real." (YIN, 2004; AMATURANGA et al, 2001).

Segundo Dubé e Paré (2003) os "Estudos de Caso" são apropriados quando o objeto de investigação é complexo e quando o fenômeno estudado não pode ser analisado fora do contexto onde ocorre. Esse método de investigação também é apropriado nos casos onde é necessária profundidade na pesquisa (DUBÉ e PARÉ, 2003; EINSENHARDT, 1989). As possibilidades de utilização do estudo de caso vão para além do descrito anteriormente. Em seu artigo, Einsenhardt (1989) argumenta e apresenta as possibilidades do Estudo de Caso para a construção de teorias.

Além disso, para Ellram (1996) o "Estudo de Caso" pode ser utilizado para: (1) explorar um determinado assunto ou problema, entendendo-o profundamente; (2) explanar sobre um fenômeno; (3) descrever um fenômeno; e (4) predizer características de um determinado fenômeno. Alguns dos propósitos para o uso do "Estudo de Caso" descrito por Ellram (1996) justificam a utilização desse método para essa pesquisa. A seguir são detalhados os procedimentos técnicos adotados para a pesquisa.

O presente artigo utilizou no seu desenvolvimento a estratégia metodológica estudo de caso exploratório, de acordo com a definição de Yin (2001). O autor evidencia que estudo de caso como estratégia de pesquisa possui uma vantagem distinta quando se faz uma questão do tipo "como" ou "por que" acerca de um conjunto contemporâneo de acontecimentos, a respeito dos quais o pesquisador tem pouco ou nenhum controle. Segundo Roesch (1999), sua adoção como estratégia de pesquisa é relevante por ser capaz de estudar em profundidade os fenômenos dentro de seu contexto, ser adequada ao estudo de processos e possibilitar explorar fenômenos a partir de vários ângulos. A abordagem a ser adotada foi qualitativa, pois a amostra utilizada não possibilita uma avaliação mais ampla. 


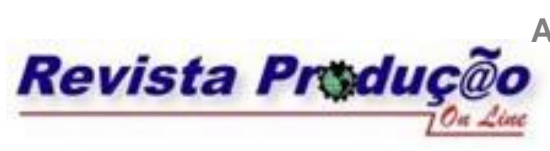

Associação Brasileira de Engenharía de Produção - ABEPRO

Universidade Federal de Santa Catarina - UFSC

www.producaoonline.org.br

ISSN 1676 - 1901 / Vol. IX/ Num.IV/ 2009

(i)

Os dados para o estudo de caso foram coletados através de coleta de campo com pessoas envolvidas no processo de recebimento da empresa. As coletas de dados foram baseadas em históricos de fornecimento dos anos de 2005 e 2006, pelos quais foi possível identificar as quantidades de produtos não conformes recebidos no período de tempo e as respectivas quantidades fornecidas. As análises foram realizadas com base em planilhas de cálculo no Microsoft Excel, construídas a partir de documentos e normas associadas à ISO/TS 16949 e Manual do FMEA $3^{\text {a }}$ edição (2002).

Na seqüência apresentam-se os resultados obtidos com o desenvolvimento do estudo de caso.

\section{Apresentação do Caso}

O estudo em questão foi realizado em três etapas: identificação dos pontos de desperdício no processo de avaliação de fornecedores, aplicação de critérios de qualidade assegurada e acompanhamento dos resultados. A seguir essas etapas serão apresentadas.

\subsection{Identificação do Processo}

O processo de liberação de materiais inicia pelo setor de Logística (Figura 1). Quando um caminhão está em processo de descarregamento de materiais, o Analista Logístico, de posse da nota fiscal, realiza a liberação fiscal do material. Após, os materiais são disponibilizados para a área de inspeção, e ficam no aguardo do setor de Qualidade para realização do procedimento. O inspetor da Qualidade inicia as inspeções e segue os critérios indicados no relatório de inspeção. Esse relatório indica todas as características e informações necessárias para que o Inspetor da Qualidade possa liberar o produto nas condições apropriadas para uso. Caso o material seja aprovado, o mesmo é identificado com uma etiqueta verde, e um cone verde é posicionado no lote, para que a Logística visualize o material disponível para armazenamento no estoque. Caso o material seja reprovado na inspeção, o mesmo é identificado com uma etiqueta vermelha e um cone vermelho é posicionado no lote, para que o Auditor da Qualidade possa encaminhar as devidas análises. As tratativas com o lote reprovado seguem os passos descritos no procedimento para controle 
de produtos não conformes.

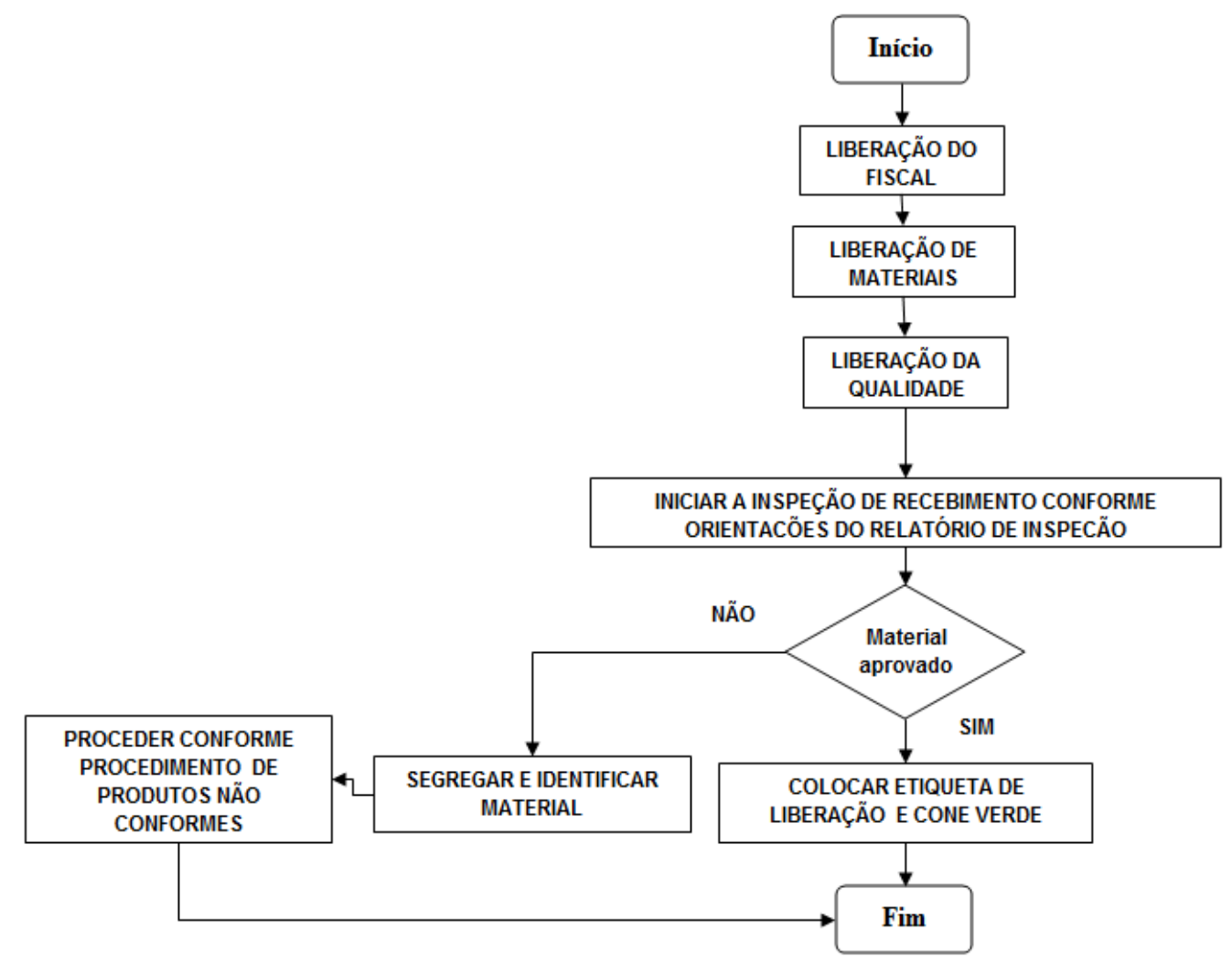

Fonte: A empresa objeto do estudo

Figura 1 - Fluxo do processo de liberação de materiais na empresa estudada.

\subsection{Identificação dos Desperdícios no Processo}

Durante o período de análise do ambiente identificou-se que a empresa empregava recursos de mão-de-obra de forma inadequada em inspeções. Isso porque, devido ao desempenho histórico de determinados fornecedores, tais inspeções não seriam necessárias. Com base nessa percepção foram analisados alguns dos desperdícios identificados à luz do STP, conforme apresentado a seguir:

- Desperdícios por Superprodução: considerando o processo de inspeção de recebimento da Qualidade como um processo produtivo de serviço para a Planta, verificou-se a inspeção de itens desnecessários, ou seja, que poderiam estar em Qualidade Assegurada, o 
que foi interpretado como superprodução da tarefa de inspeção.

- Desperdícios por Transporte: verificou-se a necessidade de movimentação dos materiais a serem disponibilizados para inspeção no recebimento. Considerando a possibilidade de realização de inspeções em locais mais próximos essa se tornou uma fonte potencial para eliminação de desperdícios.

- Os desperdícios no Processamento: verificou-se que o processo de inspeção de recebimento de produtos, dos quais muitos poderiam estar em Qualidade Assegurada, corresponde às atividades de transformação desnecessárias para que o produto adquira suas características básicas de qualidade. Ou seja, estando em níveis de qualidade apropriados, o processo de inspeção resultava em ações desnecessárias sobre o produto.

- Os desperdícios no Movimento: quando os materiais eram recebidos pela equipe de Logística, os mesmos eram disponibilizados na área de inspeção da qualidade. Posteriormente, a equipe da Qualidade realizava as inspeções e, estando os materiais aprovados, os disponibilizava novamente para a equipe de Logística realizar o armazenamento dos mesmos. Pode-se verificar um excesso de movimentação desnecessária nesta etapa do processo.

- Os desperdícios por Espera: devido ao elevado número de materiais que aguardavam a inspeção da equipe da Qualidade, alguns operadores ficavam sem atividade em certos momentos, gerando custos para a empresa devido à ociosidade. Um fator identificado foi a falta de sincronização da tarefa anterior com a posterior e falta de critérios para inspeção.

- Os desperdícios por Estoque: verificou-se que a demora no processo de inspeção de recebimento dos materiais impactava o lead time de disponibilização para o processo de montagem. Dessa forma, prejudicava a possibilidade de elevar o giro dos estoques.

\subsection{Preparação da Abordagem de Qualidade Assegurada por Meio do Índice Ppk}

A necessidade de se estabelecer uma nova abordagem no processo de inspeção de recebimento da empresa ocorreu devido à alta demanda de produtos recebidos. $\mathrm{Na}$ forma anterior à abordagem ora proposta, todos os produtos recebidos eram inspecionados e com o mesmo critério, o que impedia um foco mais detalhado em fornecedores que apresentassem maiores índices de problemas. 


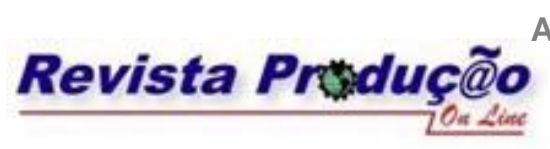

Associação Brasileira de Engenharía de Produção - ABEPRO

Universidade Federal de Santa Catarina - UFSC

www.producaoonline.org.br

ISSN 1676 - 1901 / Vol. IX/ Num.IV/ 2009

(i)

Convém observar que, por características do ambiente estudado, cada item recebido somente poderia ser fornecido por uma empresa, conforme contratos firmados, e que a substituição de fornecedores requer comunicação prévia aos demais elos diretos na cadeia industrial.

A abordagem proposta foi construída por uma equipe multifuncional, a qual foi definida após a discussão sobre a necessidade de aperfeiçoamento das operações do processo de recebimento de materiais.

Uma reunião foi realizada previamente com os membros do projeto, para discussão dos possíveis métodos a serem utilizados na abordagem, e posterior preparação da proposta para apresentação a Gerência da Planta. Após aprovada a proposta, a equipe detalhou as etapas necessárias para realização do projeto. $\mathrm{O}$ mesmo teve quatro reuniões intermediárias antes do fechamento e apresentação final. Durante essas reuniões foram trocados conhecimentos técnicos entre os membros da equipe, visando adequar a proposta de método à realidade e às práticas da organização.

Houve pré-teste dos procedimentos, apenas em nível de cálculo dos dados, para verificar se o modelo proposto atenderia as necessidades. À medida que o método era desenvolvido, os resultados foram sendo refinados e seu desempenho testado com base em registros históricos do processo de inspeção e dos cadastros de fornecedores, buscando obter validade para a abordagem proposta.

O projeto teve um tempo de duração de dois meses, desde a concepção até a apresentação final. Após a aplicação e o monitoramento dos resultados obtidos, sugeriu-se à empresa que o método proposto fosse divulgado às demais plantas da América do Sul. Esta sugestão visava ao compartilhamento das práticas e soluções possíveis, já que a rotina das demais plantas são similares em termos de processo de recebimento de materiais.

\subsection{A Abordagem de Qualidade Assegurada por Meio do Índice Ppk}

A abordagem de Qualidade Assegurada proposta à empresa visava utilizar os princípios recomendados pelo Manual do FMEA $3^{\mathrm{a}}$ edição (2002), os quais consideram o cálculo do desempenho de determinado fornecedor (Ppk), em um determinado período de tempo. A seguir, apresentam-se os procedimentos aplicados no presente estudo e as etapas 
para definição do índice de desempenho utilizado:

1a Etapa: com base nos registros de itens e no cadastro de fornecedores, foram calculadas as taxas de defeito por componente, calculada pela expressão (2):

$$
\text { Taxa de defeitos }=\frac{\text { Quantidade de itens não conformes }}{\text { Quantidade de itens recebidos }}
$$

- $\mathbf{2}^{\mathbf{a}}$ Etapa: de posse das taxas de defeito, para cada item-fornecedor foi obtida a estimativa do Ppk, seguindo o procedimento especificado no Manual do FMEA $3^{\text {a }}$ edição (2002), calculada pela expressão (3):

$$
P p k=\frac{\Phi^{-1}(1-\text { Taxa de Defeitos })}{3}
$$

onde $\Phi^{-1}$ representa o escore $\mathrm{Z}$ associado à distribuição Normal padronizada.

Por exemplo, se para um dado fornecedor a quantidade de peças não conformes no período foi de 5 unidades e o total de peças recebidas no período foi 1000, então a taxa de defeitos será 0,005 (5.000 PPM - partes por milhão), o que corresponde a um escore Z de 2,81 e. finalmente, a uma estimativa de desempenho de $\mathrm{Ppk}=2,81 / 3=0,937$.

- $3^{\text {a }}$ Etapa: de posse das estimativas de desempenho, foi aplicado o critério estabelecido no manual. Conforme esse critério amostras dos fornecedores deveriam ser aprovadas se o índice de Ppk fosse maior ou igual a 1,67, o que corresponde a menos de 10 PPM.

- $4^{a}$ Etapa: Decisão e seleção de níveis de fornecedores: os resultados obtidos foram analisados e validados com o corpo gestor da empresa, sendo estabelecidos os seguintes procedimentos:

a) os itens que atenderam ao critério estabelecido na $3^{\text {a }}$ Etapa passaram ao status de Qualidade Assegurada (QA) e não necessitariam passar mais pela área da qualidade (Inspeção de Recebimento);

b) mensalmente a Área de Qualidade emitiria uma lista indicando todos os itens em Qualidade Assegurada;

c) a Área da Logística, ao conferir o material recebido, estando este em QA, o identificará com a data de entrada, e o alocará diretamente no estoque, reduzindo assim o volume de peças no recebimento;

d) desvios seriam monitorados e detectados no processo produtivo e comunicados à 


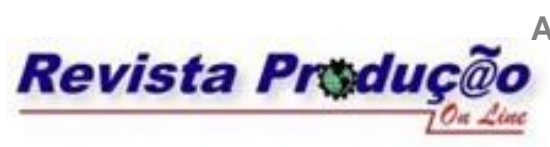

Associação Brasileira de Engenharia de Produção - ABEPRO

Universidade Federal de Santa Catarina - UFSC

www.producaoonline.org.br

ISSN 1676 - 1901 / Vol. IX/ Num.IV/ 2009

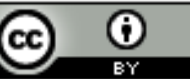

Área de Qualidade para tomada de providências.

\subsection{Análise de Resultados Após Aplicação do Novo Critério}

Considerando uma carteira de aproximadamente 229 itens produtivos, o seguinte quadro foi identificado:

- 101 itens foram classificados para o status QA. Desses, após a avaliação da empresa:

- 66 itens foram classificados para o status QA;

○ 25 itens considerados importantes poderiam entrar em qualidade assegurada, mas a empresa optou apenas por reduzir a freqüência de amostragem em função de sua criticidade e aplicação;

○ 10 itens já possuíam amostragem reduzida e permaneceram nesse mesmo critério;

- 15 itens considerados importantes foram selecionados para análise de redução de amostragem juntamente com o departamento de Engenharia;

- 88 itens foram classificados para inspeção de recebimento normal;

- 25 itens foram identificados para avaliação por meio de auditorias quinzenais nos fornecedores "on site".

Observa-se que nem todas as decisões tomadas pela empresa foram fruto da análise do indicador de desempenho, mas sua utilização permitiu questionar o procedimento vigente e identificar ações focadas para diferentes perfis de itens fornecidos, sendo este considerado, portanto, um ganho paralelo da abordagem proposta.

A aplicação da abordagem na empresa foi acompanhada por cerca de um ano, no qual a empresa continuou com a aplicação da abordagem proposta e focalizou esforços em ações de melhoria de fornecedores. Para fins de comparação, a Figura 2 apresenta uma comparação da situação inicial de implantação. Observe-se a redução de 55 pontos percentuais no perfil de itens a serem inspecionados pelo padrão então vigente na empresa. 


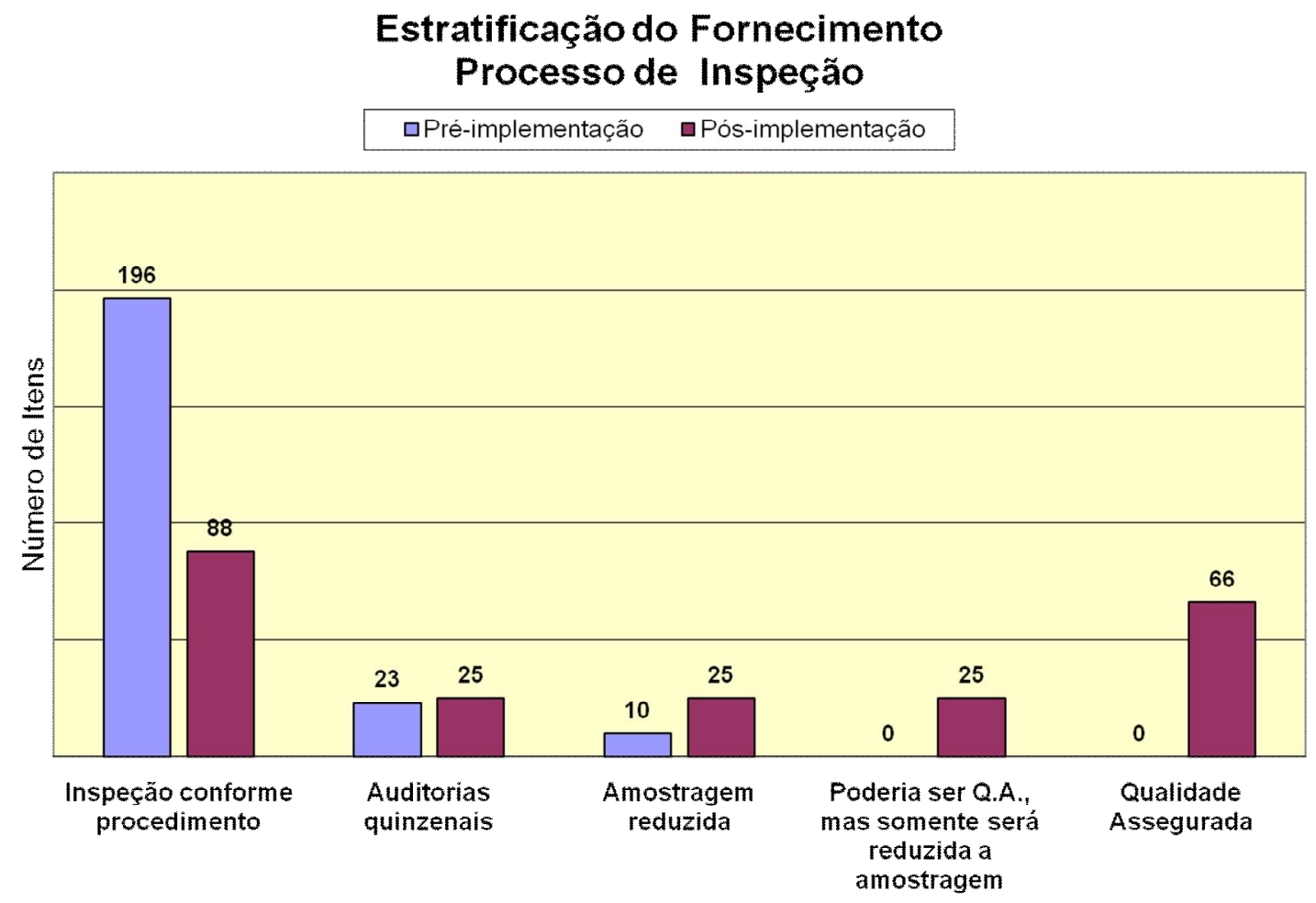

Figura 2 - Alteração no status da inspeção de itens recebidos na implantação da abordagem.

Fonte: A empresa objeto do estudo

No decorrer do ano em questão, os esforços de focalização na qualificação de fornecedores mostraram-se efetivos, permitindo dar maior atenção àqueles que demandavam maior esforço de melhoria em seus processos ou produtos. A Figura 3 apresenta comparativamente a evolução dos resultados ao longo desse período. Observe-se a manutenção dos níveis de itens com auditoria quinzenal e amostragem reduzida, conforme a decisão estratégica da empresa. Observe-se também a redução do número de itens sob inspeção normal em cerca de 79 pontos percentuais em relação ao processo anteriormente aplicado, no decorrer de um ano. 


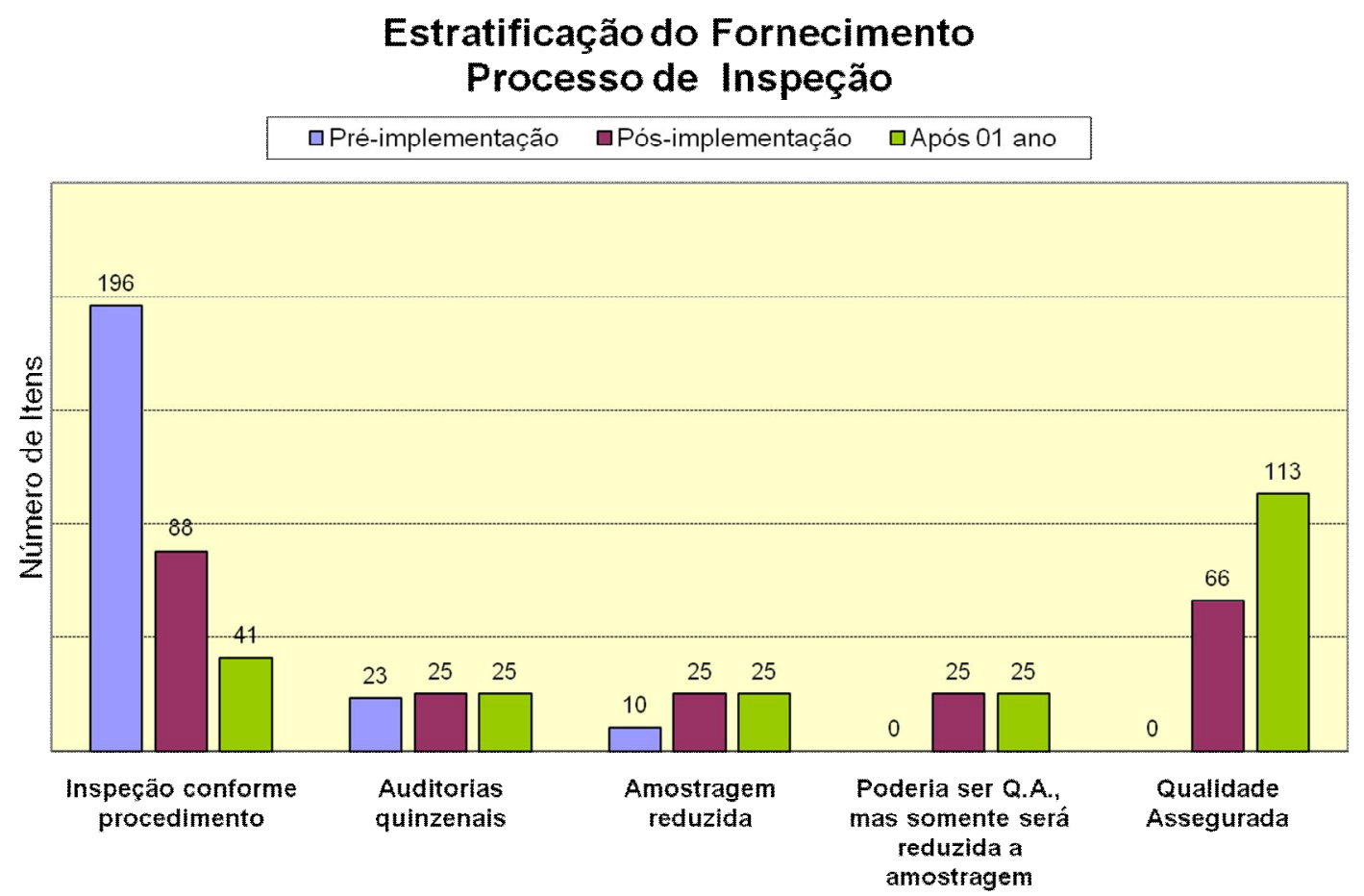

Figura 3 - Evolução dos status de fornecedores durante um ano de implantação da abordagem.

Fonte: A empresa objeto do estudo

Outro indicador considerado relevante pela empresa foi a redução do ciclo logístico completo, desde o recebimento dos materiais, passando pela inspeção de recebimento e finalizando no armazenamento dos materiais. Sob esse aspecto, o ganho estimado foi de $32,15 \%$ de redução no ciclo, o que representa cerca de 30 dias de operação economizados e destinados a outras atividades de maior agregação de valor para a empresa (Figura 4). 


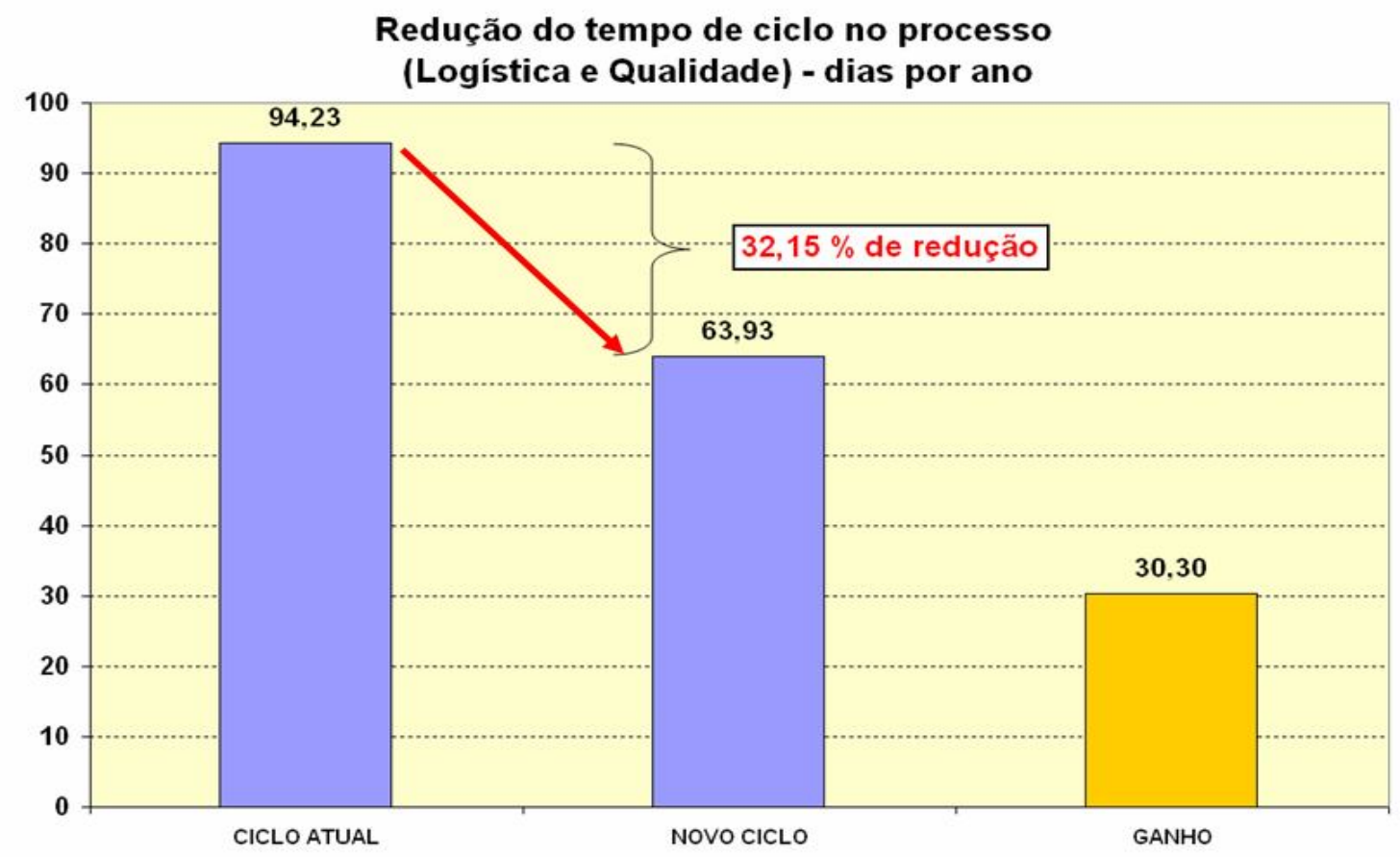

Figura 4 - Redução do tempo de ciclo no processo (em dias por ano) desde a implantação da abordagem. Fonte: os autores

\section{Análise e Discussão}

O estudo realizado apresenta a aplicação de uma alternativa de qualificação de fornecedores fundamentada em conceitos do Controle Estatístico de Processos. Dentre os principais ganhos observados durante o estudo podem-se destacar:

- redução de tempos de atravessamento e maior agilidade no fluxo de recebimento;

- ganho de 11,5 horas/homem por semana na Área da Qualidade;

- redução do tempo de ciclo do recebimento dos 66 itens propostos para QA, de 34,42 horas/ semana para 23,36 horas/semana;

- melhor aproveitamento de espaço físico da área de recebimento, com redução de $28 \%$ da ocupação;

- maior disponibilidade de recursos para atividades que agregam valor à empresa, tais como ação sobre fornecedores com qualificação inferior, análises de causas raízes de problemas 
e outras ações de melhoria;

- separação dos itens críticos e de impacto para a percepção de qualidade pelo cliente final.

A interação com os fornecedores foi qualificada, pois as tomadas de decisões passaram a ser realizadas por meio da utilização de dados mais precisos e alinhados com os objetivos da organização. Da mesma forma, o cliente final foi indiretamente beneficiado, pois a qualificação dos fornecedores tende a qualificar o produto final e reduzir riscos e custos sobre o abastecimento.

Como resultados paralelos do trabalho, pôde-se ter uma visão mais ampla das reais necessidades das áreas de Qualidade e de Logística no que diz respeito ao tipo de informação a ser trocado para a efetivação de sistema estruturado de melhoria de Qualidade. Após a implementação do projeto, mensalmente o Setor da Qualidade iniciou o fornecimento das listas de materiais constantes em Qualidade Assegurada, para que propiciar maior agilidade na liberação fiscal do recebimento de materiais, e consequentemente a disponibilidade do mesmo no estoque. $\mathrm{O}$ processo trouxe um resultado significativo para a unidade industrial da empresa, promovendo interação entre as áreas, na busca de soluções para o problema do recebimento. Pode-se citar o envolvimento adicional da área de Manufatura durante o estudo, pois a mesma foi afetada positivamente com a redução do lead time de fornecimento de componentes para as linhas de montagem. Assim, os tempos de espera dos materiais na área de inspeção foram significativamente reduzidos, o que impactou de forma benéfica também os riscos de paradas de linha por falta de peças, devido às altas esperas na área de inspeção. Esse ponto é crucial dado o contexto de operação da empresa, a qual adota um processo just in sequence, é imprescindível a disponibilidade dos materiais no momento do uso, sem riscos de abastecimento por falta de peças.

É relevante comentar as dificuldades encontradas e as limitações observadas para a abordagem proposta. Como dificuldades identificou-se a necessidade de tempo para coleta de dados e análise dos dados. O ambiente de trabalho da empresa é extremamente dinâmico em função da proximidade com o cliente e da operação just in sequence, requerendo tempos de resposta é extremamente rápidos, da ordem de minutos. Dada a prioridade à operação, em certos momentos fazia-se necessário interromper os trabalhos para o atendimento de outras demandas do complexo. Outro fator importante foi a necessidade de chegar-se a um consenso com relação à importância da realização do projeto. No início, houve resistências à possível 


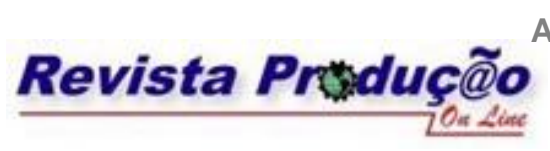

Associação Brasileira de Engenharía de Produção - ABEPRO

Universidade Federal de Santa Catarina - UFSC

www.producaoonline.org.br

ISSN 1676 - 1901 / Vol. IX/ Num.IV/ 2009

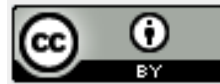

mudança dos processos, mas no decorrer dos trabalhos perceberam de modo tangível os resultados obtidos. Como limitações cabe ainda salientar: a necessidade de conhecimento no que diz respeito às análises estatísticas; o pressuposto de normalidade de distribuição dos índices, que necessita ser monitorado para evitar erros de julgamento; e a impossibilidade de generalização da abordagem ora proposta apenas com base em um caso bem sucedido.

Por fim cabe salientar a importância do projeto para o aprendizado e qualificação da equipe.

A necessidade do trabalho em conjunto e as reuniões realizadas para discussões técnicas contribuíram para um amadurecimento geral, possibilitando um entendimento dos objetivos da análise estatística dos dados, a importância do foco e os meios para atingimento dos objetivos, e os resultados gerados após sua implementação. O reconhecimento do trabalho foi visível transversalmente ao longo da organização, permitindo o encorajamento dos participantes para novos desafios e projetos futuros. Como feedback, o corpo gestor, ao verificar os resultados obtidos, sugeriu a divulgação das práticas para as demais unidades industriais da América do Sul, com o objetivo de partilhar resultados e para que as mesmas analisassem a viabilidade de implantação de abordagens semelhantes.

\section{Conclusão}

A abordagem sugerida pelo presente trabalho proporciona uma alternativa para qualificar o processo de inspeção de produtos e componentes produtivos em um sistema de recebimento. $\mathrm{O}$ estudo de caso realizado em uma empresa do ramo automotivo indicou resultados satisfatórios para a abordagem proposta, apesar dos mesmos não serem conclusivos sobre a qualidade dessa abordagem frente a outras possíveis.

De acordo com o proposto no referencial teórico, a empresa desenvolve-se utilizando técnicas de qualidade assegurada para reduzir desperdícios em seu recebimento, e focar nos fornecedores que apresentam maiores problemas. Ao mesmo tempo, busca constante desenvolvimento e aprimoramento da técnica utilizada, e de seus colaboradores.

Como reflexo deste trabalho, a organização, atualmente, pode direcionar os esforços para análises mais detalhadas do processo, na busca de novas oportunidades de redução de desperdícios. Uma vez que, atuar em um processo de manufatura Just in Sequence, exige da empresa o abastecimento do cliente diretamente na linha de produção, em sequência pré- 


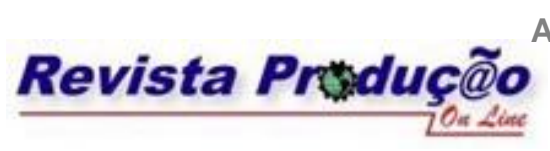

Associação Brasileira de Engenharía de Produção - ABEPRO

Universidade Federal de Santa Catarina - UFSC

www.producaoonline.org.br

ISSN 1676 - 1901 / Vol. IX/ Num.IV/ 2009

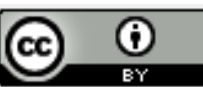

definida e em takt time determinados pelo mesmo.

Desse modo, o processo produtivo deve ser eficiente considerando: i) a redução da movimentação e o tempo consumido com a preparação das máquinas (set up) e equipamentos; ii) a gestão da linha de produção, que coloca ênfase na autonomia dos encarregados e no balanceamento da linha, na não aceitação de erros, paralisando-se a linha, se for necessário, até que os erros sejam eliminados; iii) a produção, que se baseia em grupos de trabalho, nos quais trabalhadores multifuncionais iniciam e terminam um ou mais tipos de produtos, que serão utilizados pelo grupo seguinte; iv) a responsabilidade pela qualidade, que é transferida para a produção e é dada ênfase ao controle da qualidade na fonte, adotando os princípios de controle da qualidade total; v) e também a redução dos tempos do processo, como forma de conseguir flexibilidade, visto que os tempos consumidos com atividades que não acrescentam valor ao produto devem ser eliminados, enquanto os tempos consumidos com atividades que geram valor ao produto devem ser utilizados de forma a maximizar a qualidade dos produtos produzidos.

Deste modo, foi possível identificar classes de fornecedores os quais puderam ser avaliados e categorizados dados seus históricos de fornecimento e criticidade do produto, a fim de reduzirem-se os tempos de processo desde o recebimento até a disponibilidade à linha de produção. Assim, essa reestruturação permite à empresa focar em um processo de melhoria contínua, o qual permite constantemente avaliar seu processo de recebimento e buscar reduções de desperdício que permitam maior flexibilidade e agilidade ao processo de recebimento.

Como proposta de trabalho futuro sugere-se a continuidade do acompanhamento do trabalho, analisando a evolução do desempenho dos fornecedores, de modo a registrar os elementos de decisão e os limitantes ao crescimento dos indicadores de desempenho. Também observa-se que a sistemática adotada poderia ser aplicada em outros processos produtivos dessa ou de outras empresas, de modo que a comparação com outros casos poderia trazer novos insights para o tema.

Finalizando, os autores agradecem à empresa estudada e a seus gestores pela atenção e disponibilização das informações necessárias para o desenvolvimento deste trabalho acadêmico. 


\section{Referências}

AKAO, Y.; MIZUNO, S. QFD: the customer-driven approach to quality planning and deployment. Tokyo: Asian Productivity Organization, 356p. 1994.

AMARATUNGA, Dilanthi, BALDRY, David, SARSHAR, Marjan, NEWTON, Rita. Quatitative and Qualitative Research in the built environment: application of "mixed" research approach, Work Study, Emerald, Vol 51, n 1, p. 17-31, 2002.

ANFAVEA - Associação Nacional dos Fabricantes de Veículos Automotores. Disponível via WWW em <http://www.anfavea.com.br>. Acessado em: março de 2008.

CAMPOS, V. F. Gerência da Qualidade Total. Rio de Janeiro: Editora Bloch, 1990.

DAHLMANN, F.; BRAMMER, S.; MILLINGTON, A. Environmental management in the United Kingdom new survey evidence. Management Decision. Vol. 46 No. 2, p. 264-283. 2008.

DUBÉ, Line, PARÉ, Guy, Rigor in Information Systems Positivist Case Research: Current Practices, Trends and Recomendations, MIS Quaterly, v.27, n.4, p.597-635, 2003.

EINSENHARDT, Kathleen M. Building theories from case study research. Academy of Management Review. Stanford, v.14, p.532-550, 1989.

ELLRAM, Lisa M. The use of the case study method in logistics research. Journal of Business Logistics. Arizona, v.17, n.2, p.93-138, 1996.

FENG, M. ; TERZIOVSKI, M.; SAMSON, D. Relationship of ISO 9001-2000 quality system certification with operational and business performance: a survey in Australia and New Zealand-based manufacturing and service companies. Journal of Manufacturing Technology Management. Vol. 19 No. 1, p. 22-37. 2008.

FURLAN, A.; GRANDINETTI, R.; CAMUFFO, A. How do subcontractors evolve? International Journal of Operations \& Production Management. Vol. 27 No. 1,, p. 69-89. 2007.

GILBRETH, F.; KENT, R. Motion Study: A Method For Increasing The Efficiency Of The Workman. New York: Kessinger Publishing, LLC. 140p. 1911.

HAWKEN, P.; LOVINS, A.; LOVINS, L. Capitalismo natural: criando a próxima revolução industrial. São Paulo: Cultrix, 358 p. 2000.

JOHNSON, D. Empirical study of second-tier automotive suppliers achieving QS-9000 Reference No 718. International Journal of Operations \& Production Management. Vol. 22, No. 8, p. 902-928. 2002.

JOHNSON, D.; SUN, J.; JOHNSON, M. Integrating multiple manufacturing initiatives: challenge for automotive suppliers. Measuring Business Excellence. Vol. 11 No. 3, p. 41-56, 2007.

JURAN, J. M. A qualidade desde o projeto: os novos passos para o planejamento da qualidade em produtos $e$ serviços. São Paulo: Pioneira. 551p. 1992.

MANUAL DE FMEA. 3. Edição São Paulo: IQA, 85 p. 2002.

MATSON, J.; MATSON, J. Just-in-time implementation issues among automotive suppliers in the southern USA. Supply Chain Management: An International Journal. Vol. 12. No. 6. P. 432-443. 2007.

MESQUITA, L.; LAZZARINI, S.; CRONIN, P. Determinants of firm competitiveness in Latin American emerging economies: evidence from Brazil's auto-parts industry. International Journal of Operations \& Production Management. Vol. 27. No. 5. p. 501-523. 2008.

MONTGOMERY, D. Introdução ao controle estatístico da qualidade. 4. ed. Rio de Janeiro: LTC. 513 p. 2004. 


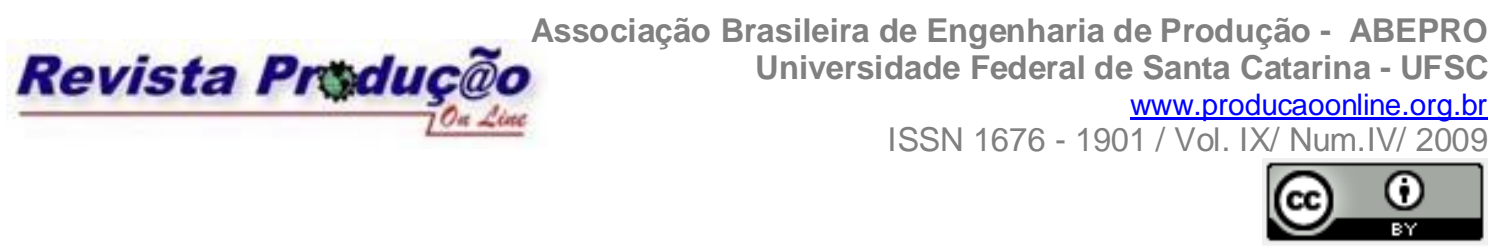

MONTGOMERY, D.; RUNGER, G. Estatística aplicada e probabilidade para engenheiros. 2. ed. Rio de Janeiro: LTC, 2003.

RAO, P.; HOLT, D. Do green supply chains lead to competitiveness and economic performance? International Journal of Operations \& Production Management. Vol. 25. No. 9. p. 898-916. 2005.

ROESCH, S. M.A. Projetos de estágio e de pesquisa em administração: guias para estágios, trabalhos de conclusão, dissertações e estudos de caso. São Paulo: Atlas,1999.

SHINGO, S. Sistema Toyota de produção do ponto de vista da engenharia de produção. 2. ed. Porto Alegre: Bookman, 1996.

SIMPSON, D.; POWER, D.; SAMSON, D. Greening the automotive supply chain - a relationship perspective International Journal of Operations \& Production Management. Vol. 27. No. 1. p. 28-48. 2007.

VERGARA, S. Projetos e relatórios de pesquisa em administração. São Paulo: Atlas, 2000.

WU, Y. Lean manufacturing - a perspective of lean suppliers. International Journal of Operations \& Production Management. Vol. 23 No. 11. p. 1349-1376. 2003.

YIN, Robert K. Estudo de caso: planejamento e métodos. Porto Alegre: Bookman, 2001.

Artigo recebido em 13/04/2009 e aceito para publicação em 15/12/2009. 